\title{
Bridging silos: Taking a page from the Alzheimer playbook
}

\author{
Muath Bishawi, MD, MPH, ${ }^{\mathrm{a}}$ and Nicholas D. Andersen, $\mathrm{MD}^{\mathrm{b}}$

\footnotetext{
From the ${ }^{\mathrm{a} D i v i s i o n}$ of Cardiothoracic Surgery, Duke University Medical Center, Durham, NC; and the ${ }^{\mathrm{b}}$ Department of Cardiac Surgery, Boston Children's Hospital, Harvard Medical School, Boston, Mass.

Disclosures: Authors have nothing to disclose with regard to commercial support.

Received for publication Oct 17, 2017; accepted for publication Oct 26, 2017; available ahead of print Dec 6, 2017.

Address for reprints: Nicholas D. Andersen, MD, Boston Children's Hospital, Department of Cardiac Surgery, 300 Longwood Ave, Bader 273, Boston, MA 02115 (E-mail: Nicholas.Andersen@ cardio.chboston.org).

J Thorac Cardiovasc Surg 2018;155:966-7

$0022-5223 / \$ 36.00$

Copyright $\Subset 2017$ by The American Association for Thoracic Surgery

https://doi.org/10.1016/j.jtcvs.2017.10.112
}

Postoperative neurocognitive dysfunction continues to represent one of the most challenging and important limitations of modern cardiac surgery. ${ }^{1}$ Recent studies in the neurology literature have reported reduced serum levels of glial cell line-derived neurotrophic factor (GDNF), a protein with putative neuroprotective properties, in patients with Alzheimer disease. ${ }^{2}$ Spurred by these findings, Duan and colleagues ${ }^{3}$ prospectively measured preoperative and postoperative serum GDNF levels in 80 patients undergoing mitral valve replacement for rheumatic disease and correlated these GDNF levels with postoperative cognitive dysfunction (POCD), as assessed by neuropsychologic testing 7 days after surgery. In the current issue of the Journal, Duan and colleagues ${ }^{3}$ report their findings of reduced levels of GDNF at 2 and 7 days after surgery in patients with POCD, although baseline GDNF levels were similar between patients who did and did not develop POCD. Duan and colleagues ${ }^{3}$ concluded that GDNF may represent a novel biologic predictor of neurocognitive dysfunction after heart surgery, as well as a therapeutic target.

The findings of this study should be viewed as preliminary and interpreted with caution for several reasons. First, the mechanism by which GDNF affects neurocognitive function remains unknown. Interestingly, GDNF levels were found to be reduced in the serum but increased in the cerebrospinal fluid of patients with Alzheimer disease relative to healthy control patients, ${ }^{2}$ somewhat complicating the use of GDNF as a biomarker or therapeutic target. Further, GDNF therapy has been tested in several clinical trials in patients with Parkinson disease, and despite strong early enthusiasm, phase II clinical trials have failed to demonstrate clinical efficacy. ${ }^{4}$ Second, postoperative assessment of neurocognitive dysfunction 7 days after surgery contains several limitations, because patients are still in the early recovery stage, and later assessments of neurocognitive function are therefore necessary. ${ }^{5}$ The addition of imaging data to identify silent brain injury as an independent contributor to neurocognitive dysfunction should also ideally be obtained and controlled for in all cases. 5,6

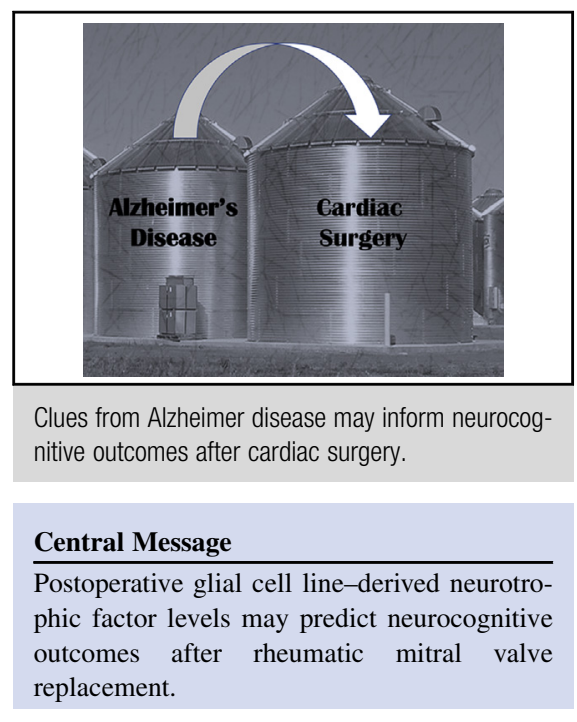

See Article page 958

Finally, the clinical utility of GDNF as a predictor of POCD appears weak, given that GDNF levels did not decrease in patients with POCD until after the operation, suggesting that assessment of GDNF levels before embarking on surgery will not provide any additional predictive or prognostic information.

Significantly more research will be required to translate the association between postoperative serum GDNF levels and POCD into a clinically relevant tool for the early diagnosis and treatment of postoperative neurocognitive dysfunction in a manner that will improve postoperative outcomes. Duan and colleagues, ${ }^{3}$ however, are to be congratulated in carrying out their prospective study. Their efforts may be critical in initiating an evidence-based, biologic treatment for an important postoperative complication. Perhaps more importantly, the ingenuity of applying knowledge gained in other disciplines to solve problems

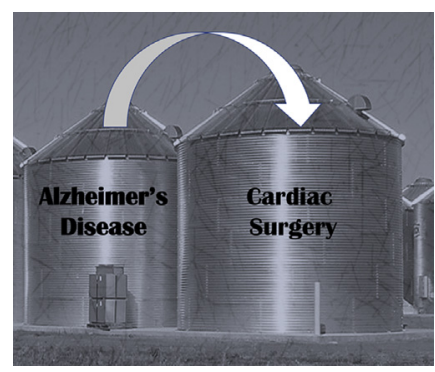

FIGURE 1. Clues from Alzheimer disease may inform neurocognitive outcomes after cardiac surgery. 
in our specialty is of paramount importance and highlights the need to link research between medical fields, rather than remaining in isolated clinical silos (Figure 1).

\section{References}

1. van Dijk D, Keizer AM, Diephuis JC, Durand C, Vos LJ, Hijman R. Neurocognitive dysfunction after coronary artery bypass surgery: a systematic review. $J$ Thorac Cardiovasc Surg. 2000;120:632-9.

2. Straten G, Eschweiler GW, Maetzler W, Laske C, Leyhe T. Glial cell-line derived neurotrophic factor (GDNF) concentrations in cerebrospinal fluid and serum of patients with early Alzheimer's disease and normal controls. J Alzheimers Dis. 2009;18:331-7.
3. Duan X, Zhu T, Chen C, Zhang G, Zhang J, Wang L, et al. Serum glial cel line-derived neurotrophic factor levels and postoperative cognitive dysfunction after surgery for rheumatic heart disease. J Thorac Cardiovasc Surg. 2018;155: 958-65.e1.

4. Sidorova YA, Saarma M. Glial cell line-derived neurotrophic factor family ligand and their therapeutic potential [in Russian]. Mol Biol (Mosk). 2016;50:589-98.

5. Knipp SC, Weimar C, Schlamann M, Schweter S, Wendt D, Thielmann M, et al Early and long-term cognitive outcome after conventional cardiac valve surgery. Interact Cardiovasc Thorac Surg. 2017;24:534-40.

6. Sun X, Lindsay J, Monsein LH, Hill PC, Corso PJ. Silent brain injury after cardiac surgery: a review: cognitive dysfunction and magnetic resonance imaging diffusion-weighted imaging findings. J Am Coll Cardiol. 2012;60:791-7. 